\title{
Assessing disorganized attachment representations: a systematic psychometric review and meta-analysis of the Manchester Child Attachment Story Task
}

DOI:

10.1080/14616734.2018.1429477

\section{Document Version}

Accepted author manuscript

Link to publication record in Manchester Research Explorer

Citation for published version (APA):

Allen, B., Bendixsen, B., Fenerci, R. B., \& Green, J. (2018). Assessing disorganized attachment representations: a systematic psychometric review and meta-analysis of the Manchester Child Attachment Story Task. Attachment and Human Development. https://doi.org/10.1080/14616734.2018.1429477

Published in:

Attachment and Human Development

\section{Citing this paper}

Please note that where the full-text provided on Manchester Research Explorer is the Author Accepted Manuscript or Proof version this may differ from the final Published version. If citing, it is advised that you check and use the publisher's definitive version.

\section{General rights}

Copyright and moral rights for the publications made accessible in the Research Explorer are retained by the authors and/or other copyright owners and it is a condition of accessing publications that users recognise and abide by the legal requirements associated with these rights.

\section{Takedown policy}

If you believe that this document breaches copyright please refer to the University of Manchester's Takedown Procedures [http://man.ac.uk/04Y6Bo] or contact uml.scholarlycommunications@manchester.ac.uk providing relevant details, so we can investigate your claim.

\section{OPEN ACCESS}




\title{
Running Head: PSYCHOMETRIC REVIEW OF THE MCAST
}

Assessing Disorganized Attachment Representations:

A Systematic Psychometric Review and Meta-Analysis

of the Manchester Child Attachment Story Task

\author{
Brian Allen ${ }^{1,2}$ \\ Brianna Bendixsen ${ }^{2}$ \\ Rebecca Babcock Fenerci ${ }^{1}$ \\ Jonathan Green ${ }^{3}$
}

Corresponding Author: B. Allen, Center for the Protection of Children, Penn State Children's Hospital, 500 University Drive, Hershey, PA 17033, Email: ballen1 @hmc.psu.edu

${ }^{1}$ Penn State Children's Hospital, Hershey, PA, USA

${ }^{2}$ Penn State College of Medicine, Hershey, PA, USA

${ }^{3}$ University of Manchester, Manchester, England, UK 


\begin{abstract}
Narrative story stem measures are increasingly popular for the assessment of attachment representations among early school-age children. Given their clinical and theoretical importance, disorganized representations are typically a focus of assessment procedures. The Manchester Child Attachment Story Task (MCAST) is one such measure. A systematic literature review and meta-analysis was conducted to evaluate the documented reliability and validity of the MCAST with a focus on assessing disorganized representations. Twenty-five studies were included in the review encompassing 1,876 children from nine countries. Results suggest that inter-rater reliability for the MCAST is acceptable and the prevalence of disorganization identified on the MCAST among various subgroups (e.g., community, clinical, adopted/maltreated) is comparable to prevalence estimates from other developmental periods using other assessment methods. In addition, prevalence of disorganization on the MCAST differed in hypothesized ways between the various subgroups. However, MCAST disorganization did not correlate in predictable ways with many constructs when relationships were examined within samples. Few studies examined the relationship of disorganization on the MCAST with parenting variables, aspects of adoption and maltreatment, and emotion regulation skills. Recommendations for further study of the MCAST and for how the tool might be integrated into clinical and developmental research are provided.
\end{abstract}




\section{Assessing Disorganized Attachment Representations: A Systematic Psychometric Review and Meta-Analysis of the Manchester Child Attachment Story Task}

Early interactions between children and their caregivers are critical to children's socialemotional development. Attachment theory provides a framework for understanding how parentchild interactions impact current and future psychological well-being. Central to this framework is the concept of the internal working model (IWM; Bowlby, 1969/1982; 1973; 1980), cognitive representations of oneself and others that are developed through interpersonal experiences. The earliest forms of IWMs are established through repeated interactions of the child with his or her caregiver, and largely develop in response to the caregiver's behaviors toward the child (Bowlby, 1973; see Bretherton \& Munholland, 2008, for a review of the IWM construct). Although IWMs serve to guide one's interpretations and behavior in social situations, they are malleable and continuously developing based on new information in the environment (Bowlby, 1988). It is important to note, however, that IWMs are increasingly stable over time as they are maintained and reinforced by experience (Bowlby, 1980; Bretherton, 2005).

\section{Disorganized Attachment Representations}

The first widely accepted assessment and classification system of attachment quality was developed by Ainsworth and her colleagues (1978) who conducted systematic behavioral observations of infants in a separation-reunion paradigm termed the Strange Situation Procedure (SSP). They identified three distinct, organized behavioral patterns designed to maintain proximity to and seek comfort from a discriminated caregiver (i.e., secure, avoidant, resistant/ambivalent). Main and Solomon $(1986 ; 1990)$ later reviewed the recordings of these observations and identified a fourth pattern of behaviors that appeared bizarre, fearful, contradictory, or otherwise unusual. They determined that these children lacked coherent and 
organized attachment behavior and labeled this phenomenon disorganized or disoriented (abbreviated as 'D'). Subsequent research demonstrated that D behavior is primarily related to caregiving that is maltreating, frightening, or otherwise threatening (see Cyr, Euser, BakermansKranenburg, \& van IJzendoorn, 2010, for a review).

Significant evidence links D classification in the SSP to aberrant development and the emergence of clinical problems (e.g., Bernard \& Dozier, 2010; Fearon, Bakermans-Kranenburg, van IJzendoorn, Lapsley, \& Roisman, 2010; Madigan, Atkinson, Laurin, \& Benoit, 2013). In addition, meta-analyses show that D classifications are more prevalent among at-risk samples (van IJzendoorn, Schuengel, \& Bakermans-Kranenburg, 1999). As such, disorganized behaviors are a common subject of research studies and the target of intervention trials in the infant mental health field.

Although IWMs have long been considered the result of the caregiving one received (Bowlby, 1969/1982), a seminal paper by Main, Kaplan, and Cassidy (1985) brought renewed attention to the construct. They argued that the observable attachment behavior of infants in the SSP were outward manifestations of a rudimentary IWM. In other words, infants have some form of mental representation of the caregiver and their behavior reflects their understanding of that relationship. More specifically, the attachment behavior demonstrated in the SSP reflects the child's attachment representations, which are conceptualized as cognitive scripts that estimate a caregiver's availability and responsiveness to one's distress and allow the child to adapt his/her behavior accordingly (Waters \& Waters, 2006). As such, disorganized behavior in the SSP can be conceptualized as the observable manifestation of a disorganized attachment representation. Given this proposition, one may hypothesize that $\mathrm{D}$ representations should be related to the same untoward consequences connected to D behavior in the SSP. Indeed, representational measures 
for childhood, adolescence, and adulthood typically document that D representations, or analogous constructs (e.g., Unresolved [U] state of mind on the Adult Attachment Interview [AAI; George, Kaplan, \& Main, 1985]) are linked to concurrent and future emotional and behavioral problems, as well as a history of maltreatment or personal loss (Hesse, 2016; Madigan, Brumariu, Villani, Atkinson, \& Lyons-Ruth, 2016).

\section{Assessing Attachment Representations in Early School-Aged Children}

Classical separation-reunion procedures (e.g., SSP) often have diminished sensitivity in detecting and classifying attachment behavior beyond 3 to 4 years of age (Solomon \& George, 2016). Although some separation-reunion procedures are available and validated for an older age range (e.g., Main \& Cassidy, 1988), a higher threshold is necessary to activate the attachment system (e.g., prolonged length of separation from the caregiver). Moreover, school-aged children have often developed a more flexible and sophisticated behavioral repertoire for communicating with caregivers once the attachment system is activated, which can make classifying the child's observable (behavioral) attachment strategy more difficult (Solomon \& George, 2016). Given these challenges, assessment of attachment representations may be a particularly useful method for understanding attachment organization in this age group.

One of the more popular approaches to assessing school-aged children's attachment representations is the narrative story stem technique. This method involves the assessor providing the child with the beginnings of several story vignettes (i.e., stems) and having the child finish the stories. Within these procedures the stem typically sets up an attachment behavior eliciting situation (e.g., an injury, a nightmare) and the child's resolution of this situation is believed to reflect his or her attachment representations. For instance, a coherent narrative that includes the child seeking proximity to a caregiver who assuages his/her distress is 
believed to reflect an organized and secure representation; however, a confused, bizarre, and/or incoherent narrative is thought to reflect a disorganized representation. Oftentimes these procedures use dolls to allow the child to act out the scenarios; thus, these techniques are often referred to as "doll play" procedures. Numerous narrative story stem techniques are available in the literature, including the MacArthur Story Stem Battery (Emde, Wolf, \& Oppenheim, 2003), the Attachment Story Completion Task (Bretherton, Ridgeway, \& Cassidy, 1990), the Attachment Doll Play Assessment (George \& Solomon, 1990-2016), and the Manchester Child Attachment Story Task (MCAST; Green, Stanley, Smith, \& Goldwyn, 2000).

Although these procedures share multiple similarities, they are each different in some respects, including administration and scoring of responses. These differences can make it difficult to compare results across studies and the clinical applicability of these methods is uncertain. Solomon and George (2016) note that none of these measures have been systematically validated to date. Therefore, systematic reviews of these protocols are warranted. The current paper systematically reviews the psychometric evidence for one of these narrative story stem procedures, the MCAST, with a specific focus on examining the assessment of disorganized attachment representations.

\section{Manchester Child Attachment Story Task (MCAST)}

The MCAST (Green et al., 2000) is a narrative story stem technique that assesses attachment representations in young school-aged children (ages 4 to 9). The MCAST utilizes a standardized administration protocol where four story stems are presented to the child in a specified order and the child is asked to complete the stories while enacting the scenes using dolls. Each vignette is designed to elicit attachment representations and the assessor is instructed to deliver the stem by using situationally and emotionally congruent verbal tones to convey a 
sense of distress in the target child doll. This mild stress induction is designed to increase elicitation of attachment-related thoughts and behaviors similar to the separation phases of the SSP or the 'five adjective question' in the AAI (George et al., 1985).

The four vignettes were designed to be age-appropriate and focus on common attachment-related situations for a school-aged child. Vignette 1 depicts the child doll waking from a nightmare; vignette 2 involves the child doll falling and hurting his/her knee; vignette 3 displays the child doll having a stomachache; vignette 4 portrays the child doll getting lost while shopping with the caregiver doll. The MCAST differs from other narrative story stem techniques in that it focuses on one specific caregiver-child relationship (instead of multiple family members), emphasizes the child's identification with the doll figure (as opposed to asking the child to comment on a scene involving other children), and uses a stress induction technique whereby the clinician uses voice intonation and simulation of emotion when presenting the stem in order to highlight the distress of the child in the story.

Administrations are video recorded for later coding. Each vignette is coded along various dimensions, including the child's proximity seeking to the caregiver, the caregiver's behavior, and the resolution of the child's distress (Green, Stanley, Goldwyn, \& Smith, 2016). The MCAST was specifically designed for practice and research with clinical populations and thus great attention in the manual is given to the conceptualization and coding of a child's disorganized attachment representations. MCAST 'D' codes are conceptually derived from the nature of disorganized behavioral phenomena seen in the SSP and the importance of narrative disruption during attachment themes identified in the AAI; both adapted for the story stem context during development and validation studies (Green, Stanley, Smith \& Goldwyn 2000, 2016). They include coding of 'episodic' disruption of the attachment narrative, 'pervasive' 
disorganization without an identifiable strategy, and 'bizarre content without resolution' in the story completion. The coding scheme identifies a dimensional level of disorganization observed across vignettes (denoted here as the 'Total D' score) as well as a categorical D classification. A predominant strategy is assigned for each vignette (standard four-way scheme: secure, avoidant, ambivalent, disorganized) and rules are provided for consolidating information across the vignettes to arrive at an overall classification. A formal training and certification process are in place to ensure those wishing to use the MCAST meet administration and coding reliability standards.

\section{Hypotheses}

The extant research on D classifications and representations provide a useful background for the development of hypotheses related to the MCAST.

1. Approximately $15 \%$ of infants from non-risk and non-clinical samples are classified D during separation-reunion procedures, whereas the prevalence in at-risk samples, broadly conceived, is estimated at $34 \%$ with prevalence estimates in maltreated samples estimated as high as $48 \%$ (van IJzendoorn et al., 1999). When looking at the AAI, similar prevalence rates are found, with $18 \%$ of those in non-clinical samples and $32 \%$ of those in at-risk samples being classified U (Bakermans-Kranenburg \& van IJzendoorn, 2009). Therefore, it seems reasonable to hypothesize that the prevalence of D classifications on the MCAST should resemble those of analogous constructs from other developmental periods.

2. Multiple studies identify child maltreatment as a significant risk factor for the development of D behavior among infants and preschool-aged children (Cyr et al., 2010). There is, of course, a connection between maltreatment experiences and U classification on the AAI, as the individual must have experienced trauma or loss to qualify for a $U$ classification, although 
such a history is not sufficient grounds for a U classification. Correspondingly, it is hypothesized that child maltreatment results in greater disorganization of attachment representations and, therefore, increases the likelihood of disorganization on the MCAST.

3. There is a well-established link between attachment disorganization and clinical problems. Meta-analyses establish a significant connection between infant D classification and externalizing problems (Fearon et al., 2010); however, findings connecting D classification to internalizing problems in childhood are mixed (Groh, Roisman, van IJzendoorn, BakermansKranenburg, \& Fearon, 2012; Madigan et al., 2013). A recent meta-analysis examining representational measures among children and adolescents found a medium effect for the relationship between disorganization and externalizing problems $(d=.58)$ and internalizing problems $(d=.47$; Madigan et al., 2016). Similarly, adults classified U on the AAI are significantly more likely to display internalizing and externalizing problems (BakermansKranenburg \& van IJzendoorn, 2009). The preponderance of evidence leads one to hypothesize that disorganization on the MCAST will be associated with elevated externalizing and internalizing problems.

4. Attachment security is consistently linked with the development of core regulatory competencies such as emotion identification and regulation, and social skills/competence (Cooke, Stuart-Parrigon, Movahed-Abtahi, Koehn, \& Kerns, in press; Groh, Fearon, BakermansKranenburg, van IJzendoorn, Steele, \& Roisman, 2014). Again, similar associations are reflected in research with the AAI (Roisman, Tsai, \& Chiang, 2004; Waters, Brockmeyer, \& Crowell, 2013). It seems reasonable to expect that disorganization on the MCAST will be related to deficits with such developmental competencies. 
5. The role of parenting factors is an often studied influence on the development of attachment, particularly parental sensitivity to the child's distress. Research on the development of disorganization, however, suggests that frightening parental behavior (e.g., physically abusive, erratic and unstable) is more influential than parental sensitivity (Madigan, Moran, \& Pederson, 2006; van IJzendoorn et al., 1999). Given that attachment behavior in infancy is believed to reflect outward manifestations of rudimentary attachment representations, these same parental behaviors should be related to performance on a measure such as the MCAST. Therefore, it is hypothesized that parental behavior that is considered frightening or insensitive will be associated with disorganization on the MCAST.

\section{Method}

\section{Retrieval and Selection of Studies}

Searches were conducted of the PsycINFO and PubMed databases for entries using the words "Manchester," and "attachment" or "story." Abstracts of identified entries were perused to determine whether the article was related to the MCAST. Full articles were obtained to determine the type of work (e.g., review, original data) and whether disorganization was specifically examined. When it was unclear from the abstract whether the MCAST was used in the study, the full article was reviewed. The reference lists of examined articles were reviewed to identify any potential additional studies that were not identified in the database searches. When articles did not provide sufficient results of psychometric evaluations or other questions were present after review, the corresponding author(s) of the articles were contacted to request additional details. Articles were reviewed by BA and BB conjointly to ensure inclusion eligibility and consensus results were included in the study. Our original plan called for identifying all articles published by the end of 2015; however, during the search we identified 
two articles that were in press. In the interests of thoroughness, these articles were included. This systematic review and meta-analysis was conducted in compliance with PRISMA guidelines.

\section{Results of Literature Search}

A total of 60 documents were identified as potentially appropriate for this review (see Figure 1). Twenty-six (26) articles were removed from consideration because they did not examine the MCAST, were not obtainable in the English language, or did not present data from an empirical study (e.g., theoretical treatise, reviews, case studies). An additional 5 studies were excluded because disorganization was not examined and the studies did not provide reliability data incorporating one of the disorganization measures. An additional 4 studies were excluded because the data presented significantly overlapped with that of another included study. This overlap often occurred because a preliminary report was published prior to a full report or because the data used in one study compared two groups of children while another study examined one group in more detail. In those situations where common data were utilized in two separate reports, but each report provided relevant non-overlapping analyses, both reports were reviewed and duplicate results were only considered once. A total of 25 studies were retained for the review. Collectively, these studies reported data for 1,876 children from nine countries (Australia, England, Germany, Ghana, Italy, Norway, Scotland, South Africa, and Ukraine).

\section{Systematic Review \& Meta-Analysis}

The goal of this study was to review the quality of evidence for the psychometric properties of the MCAST. Addressing the previously stated hypotheses were possible in a number of instances using meta-analysis methodology. Unfortunately, meta-analysis was not possible in some cases for various reasons (e.g., too few studies and/or significantly heterogeneous constructs; at least 3 samples examining similar constructs were required for 
meta-analysis). In these instances the findings are systematically reviewed with a goal of providing conservative conclusions.

Meta-analysis was employed for various constructs. Results from studies were coded by two separate reviewers, $\mathrm{BB}$ and $\mathrm{RBF}$, who displayed nearly perfect agreement $(\mathrm{ICC}=1.0)$. Only one discrepancy was noted and this was resolved by discussion and consultation with a third reviewer. Event rate (odds ratio) is reported for categorical data (i.e., D classifications) and Hedges' $g$ is reported as the effect size for each meta-analysis examining differences between organized and disorganized groups on continuous outcomes. Bias-corrected Hedges' $g$ was chosen for the effect size estimate as the standardized mean difference (Cohen's $d$ ) may overestimate effects in small samples (Borenstein, Hedges, Higgins, \& Rothstein, 2009), and many of the studies employed here utilized small samples. All analyses utilized random effects models and were performed using Comprehensive Meta-Analysis v. 3.0 software.

Each analysis included examination of the funnel plot to determine whether any significant outlying studies were present. The Egger's test is reported as a metric of such potential bias. When identified, such findings are discussed in context of the analysis performed. Fail safe numbers are provided to index the potential impact of unpublished studies.

The amount of heterogeneity within studies is provided by the $Q$ statistic. In addition, we provide $I^{2}$ for analyses, which is an indication of the extent to which observed variability among studies can be attributed to differences in the studies themselves and not spurious; findings nearing 100 are considered high and suggestive of systematic differences whereas results nearing 0 are low and suggestive of highly spurious findings (Higgins Thompson, Deeks, \& Altman, 2003). If indicated by these metrics, we then performed moderator analyses using metaregression techniques. Moderators coded for the current analysis included mean age of a sample, 
gender composition, year of publication, and inter-rater reliability. The type of population from which the samples were derived was also treated as a potential moderator to examine hypothesized differences (e.g., community, clinical). It should be noted that the $Q$ statistic is also used to compare such groups during moderator analyses and should not be confused with the $Q$ statistic used to index heterogeneity among studies within a meta-analysis.

Studies relied on reports from either caregivers or teachers; however, some studies used both reporters. Including this information together would create bias as those samples with both reporters would be weighted differently than those with one reporter and creating a synthetic variable would obscure potentially relevant differences attributable to the reporter (Borenstein et al., 2009). As such, reporter was not treated as a variable in moderator analyses, but rather metaanalyses were conducted specific to outcome and reporter.

\section{Results}

\section{Meta-analysis}

The analyses that follow were performed using the meta-analysis procedure described previously.

Prevalence of D Classifications. In those samples where D classifications were assigned $(k=22)$, meta-analysis showed that $23.1 \%$ (95\% CI: $18.4 \%-28.6 \%)$ of all children were classified D. Visual inspection of the funnel plot did not suggest significant concerns related to bias and Egger's test was not significant $(t=.83, p=.42)$. Significant variability was present among the studies $\left(Q=99.34, p<.001, I^{2}=78.86\right)$; however, meta-regression showed that gender $(O R=1.02, z=1.77, p=.076)$, age $(O R=1.0, z=-.1, p=.92)$, publication year $(O R=$ 
$1.0, z=-.11, p=.91)$ and inter-rater reliability ${ }^{1}(O R=2.22, z=.66, p=.51)$ were not associated with proportion of cases classified D. To examine hypothesized differences in the rate of $\mathrm{D}$ classifications, samples were subdivided based on the type of population from which they were drawn: community ( $n=1,087)$, at-risk (e.g., maternal mental illness, poverty; $n=389$ ), adopted and/or maltreated $(n=153)$, and clinical $(n=149)$. The maltreated and adoption samples were combined as each in isolation would include an insufficient number of studies to allow for appropriate analysis. In addition, given that the adopted samples were composed of institutionalized or otherwise neglected and abused children, children from both samples shared the characteristic of being maltreated. One study identified the sample as both adopted and drawn from a clinical setting (Kočovská et al., 2012). Given that these children were qualitatively different in terms of their attachment histories from the majority of children in a clinical setting, this sample was classified in the adopted/maltreated category. Another study analyzed results by combining children from clinical and non-clinical samples (Minnis et al., 2010); this study was excluded from the categories defined above. Meta-regression showed that sample type (e.g., community, clinical) was a significant moderator $(Q=18.33, p<.001)$ and explained a large proportion of variance $\left(R^{2}=.45\right)$.

As one would expect, the community group ( $k=10$ samples) displayed the lowest percentage of children classified D (16.2\%; 95\% CI: $11.3 \%-22.8 \%)$. The at-risk group (23\%; 95\% CI: $19.1 \%-27.4 \% ; k=4$ samples) was not significantly different from the community group $(O R=1.41, z=1.02, p=.308)$; however, both the adopted/maltreated group $(36 \% ; 95 \%$ CI: $28.8 \%-43.9 \% ; O R=2.8, z=3.08, p=.002 ; k=4$ samples $)$ and the clinical group $(40.4 \%$;

\footnotetext{
${ }^{1}$ Inter-rater reliability was examined by utilizing only those studies that reported a kappa coefficient for the 4-way classification scheme. This was the most common method of reporting inter-rater reliability and was available in most studies that reported percentage agreement.
} 
95\% CI: $24.4 \%-58.9 \% ; O R=3.54, z=3.07, p=.002 ; k=3$ samples) yielded a greater

proportion of children classified D than the community group. The clinical $(O R=2.46, z=2.52$, $p=.012)$ and adopted/maltreated groups $(O R=1.88, z=3.06, p=.002)$ contained a greater proportion of children classified D than the at-risk group, although the clinical and adopted/maltreated groups did not differ amongst themselves $(O R=1.26, z=.66, p=.507)$.

Relation to Internalizing and Externalizing Problems. Six studies ( $k=7$ samples) provided data for the relationship between caregiver-rated externalizing problems and D assessed on the MCAST ( $n=847$ ). These studies collectively included examinations of outcomes such as conduct problems, aggression, and broad indices of externalizing problems. Meta-analysis provided a summary effect size of .22 which did not reach the level of statistical significance (95\% CI: $-.05-.49, Z=1.61, p=.108)$. No concerns were noted on visual inspection of the funnel plot (Egger's $t=.4, p=.71)$. However, significant variability within samples was identified $\left(Q=12,99, p=.043, I^{2}=53.81\right)$. Moderator analyses examining the potential of age, gender composition, inter-rater reliability, publication year, and sample type (clinical vs. nonclinical) to explain the variability did not yield significant results, although it is likely the case that moderator analyses were underpowered (Borenstein et al., 2009). Analyses examining teacher-reported externalizing problems included six studies $(n=862 ; k=7$ samples $)$ and provided differing results as a significant positive relationship with D was observed $(g=.285$, CI: $0-.57, Z=1.96, p=.05)$. Again, no concerns were noted regarding potential bias (Egger's $t$ $=.64, p=.55)$, although the classic fail-safe number was 10, a relatively small threshold. Again, significant variability was observed between samples $\left(Q=13.84, p=.032, I^{2}=56.64\right)$ and none of the examined moderators accounted for a significant proportion of the variability. As before, power was likely an issue with moderator analyses. 
Four studies ( $n=259 ; k=5$ samples) examined the association of $\mathrm{D}$ with caregiverreported internalizing symptoms (i.e., broad measures of internalizing problems). Results suggested a significant correlation between D and caregiver-reported concerns $(g=-.258 ; 95 \%$ CI: $-.509--.007 ; Z=-2.012, p=.044)$ and there were no noted concerns with bias (Egger's $t=$ $1.44, p=.25)$. The fail-safe $\mathrm{N}$ of 2 suggests that this finding may easily become non-significant with additional research or publication of null findings. Surprisingly, the observed relationship was in the opposite direction than hypothesized, as greater disorganization was associated with fewer internalizing symptoms. No moderator analyses were necessary $\left(Q=3.23, p=.52, I^{2}<\right.$ .001). These results were not corroborated in the analysis examining five studies of teacherreported internalizing problems ( $n=276 ; k=5$ samples). The summary effect size from this analysis was $.321(95 \% \mathrm{CI}:-.07-.713, Z=1.61, p=.108)$. There were no concerns regarding bias (Egger's $t=.61, p=.59)$ nor was there significant variability among the samples $(Q=7.51$, $\left.p=.111, I^{2}=46.76\right)$. Examination of the confidence intervals shows that there was significant disagreement between caregivers and teachers regarding the relationship between $\mathrm{D}$ and internalizing concerns. This is not altogether unexpected as caregivers and teachers are commonly found to disagree on the rate of a child's internalizing concerns (e.g., Berg-Nielsen, Solheim, Belsky, \& Wichstrom, 2012).

Relation to Social Skills/Competence. Only three studies ( $n=698 ; k=4$ samples) examined the relationship between D and caregiver-reported social problems. The summary effect of .157 (95\% CI: $-.121-.434)$ was not significant $(Z=1.105, p=.269)$ and significant variability among samples was not observed $\left(Q=5.01, p=.171, I^{2}=40.12\right)$. No concerns were noted related to publication bias (Egger's $t=.85, p=.49)$. Five studies $(n=807 ; k=6$ samples) assessed teacher-reported social problems and their relation to the MCAST. The obtained 
summary effect size of .336 (95\% CI: -.009 - .681) approached the level of statistical significance $(Z=1.91, p=.056)$. No concerns were noted for bias (Egger's $t=.49, p=.65)$; however, significant variability among the samples was observed $\left(Q=13.785, p=.017, I^{2}=\right.$ 63.73). None of the examined moderators explained variability among the studies, but again, the analyses were likely underpowered.

\section{Systematic Review}

A number of the constructs of interest in this paper were not amenable to meta-analysis methodology (e.g., too few studies). These results are discussed here in the form of systematic review.

Reliability. Information regarding inter-rater reliability was provided in three distinct ways across studies: percentage agreement and kappa across raters for categorical ratings, and intraclass correlation coefficients (ICC) for continuous ratings. In most instances of categorical ratings the standard four-way scheme was used; however, there were a few studies that specifically examined a two-way scheme of organized/disorganized. It is worth noting that percentage agreement is a commonly used method of assessing inter-rater reliability that is easily understood; however, such a method is unable to correct for agreement that occurs by chance and the kappa statistic was developed to address this concern (Cohen, 1960). The kappa statistic is criticized as potentially underestimating the agreement between raters and for difficulty interpreting the statistic itself (McHugh, 2012). Therefore, both statistics are presented and evaluated here.

Inter-rater reliability was typically obtained by double coding a portion of the videos within a study. Four-way classification of MCAST attachment narratives was by far the most common form of inter-rater reliability reported. Percent agreement among raters ranged from 
$78 \%$ to $96 \%$, with the majority of reported results between $80 \%$ and $89 \%$ (see Table 1). All kappa coefficients for the four-way scheme were at least .52, with the majority above .80, a level typically identified as suggesting strong agreement (Cohen, 1960; McHugh, 2012). Inter-rater reliability of the two-way scheme was only reported three times. Results of two studies provided a high percentage of agreement, but kappa coefficients of marginal strength (Goldwyn, Stanley, Smith, \& Green, 2000; Zaccagnino, Cussino, Callerame, Perinetti, Veglia, \& Green, 2013), whereas the other study suggested much stronger agreement among the raters (Pasalich, Dadds, Hawes, \& Brennan, 2012). Only two studies reported ICC estimates evaluating the agreement between raters for the Total D score (Goldwyn et al., 2000; Pasalich et al., 2012), although one additional study reported on the use of a modified continuous score for disorganization (Hygen, Guzey, Belsky, Berg-Nielson, \& Wichstrøm, 2014). Estimates for the Total D in these studies ranged from .76 to .88, suggesting excellent inter-rater agreement (Cicchetti, 1994).

Only one study assessed stability over time of disorganized representations in the absence of a clinical intervention or other perceived agent of change. Green and colleagues (2000) reported that $69 \%$ of children classified D remained as such when the MCAST was readministered approximately 5.5 months later. The ICC estimate of the stability of the Total D score in this study was .70. A widely cited meta-analytic review by van IJzendoorn, Schuengel and Bakersman-Kranenberg (1999) included 5 studies examining the 6-month stability of D classifications during separation and reunion procedures, and found a range between $50 \%$ and $81 \%$ stability in these studies. This suggests that the stability of D classifications on the MCAST is within the bounds one would expect; however, one should avoid drawing definitive conclusions on the basis of a single study and replications are needed. 
Relation to Adoption and Maltreatment. Some of the studies attempted to identify factors that might help to understand why adopted/maltreated children were at higher risk for D classification. Pace, Cavanna, Valotti, and Zavattini (2014) found that disorganization scores among late adopted children (mean age at adoption $=5$ years) were independent of the amount of time the children had lived with the adopted caregivers. Interestingly, and counter-intuitively, they found that the earlier the age of adoption the higher the child's disorganization score. Barone, Dellagiulia, and Lionetti (in press) examined a similar issue, but assessed maltreated children removed from their caregivers and placed in institutions (mean age at admission to institution $=39$ months). Results suggested that the duration of the child's time in the institution was not related to D classifications on the MCAST. These studies collectively suggest that maltreated children's representations as assessed by the MCAST may, to a large extent, be developed prior to coming to live in substitute care and be slow to change following placement; however, more research is necessary.

Relation to Parenting Factors. Prior research documents significant associations between disorganization and parenting factors, specifically parental states of mind (most commonly measured via the AAI). Two studies examined MCAST disorganization in relation to parental AAI performance. Goldwyn and colleagues (2000) found that D classifications for children were significantly associated with biological mothers' U state of mind on the AAI (77\% agreement, $\kappa=.493)$. Only one other study examined the correlation of AAI and MCAST. Pace and colleagues (2012), utilizing a sample of adopted children and their adoptive mothers, found only one of 10 children classified D on the MCAST was living with a mother classified U on the AAI. The researchers did find a child's Total D score was strongly associated with the adoptive 
mother's score on the idealization of mother scale of the AAI (Spearman's rho $=.60$ ), but did not find associations between D and other AAI scales.

Two studies investigated relationships between disorganization and caregiver attributes. Green and colleagues (2007) found that categorically high levels of maternal expressed emotion were related to exceptionally high Total D scores on the MCAST in a clinical sample of children with externalizing problems, yet Total D was not generally associated with maternal expressed emotion $(d=.28)$. The high percentage of D classifications in this particular clinical sample (56.7\%) may have restricted the range of Total D scores, thereby decreasing the ability to identify associations with parental expressed emotion. In a study of maltreated and institutionalized children, Barone and colleagues (in press) did not find associations between D classifications and caregivers' reported helplessness as a caregiver; however, children's preferred professional caregivers within the institution were surveyed as opposed to biological caregivers. Two studies examined the relationship between disorganization and observable parenting behaviors in community samples and neither found a significant relationship (Matias, O'Connor, Futh, \& Scott, 2014; Pritchett, Minnis, Puckering, Rajendran, \& Wilson, 2014).

Relation to Emotion Regulation. Only three of the reviewed studies examined emotion regulation, which includes skills such as emotion identification and coping with negative emotion (Southam-Gerow, 2013), and each of the studies used child-based tasks as the criterion measures. All three of the studies noted that disorganization was related to poor performance on emotion identification tasks, with effect sizes ranging from medium to large (Barone \& Lionetti, 2012a; Colle \& Del Giudice, 2011; Zaccagnino et al., 2013). As for coping strategies, Zaccagnino et al. (2013) found disorganization was positively correlated with aggressive problem-solving. Results from Colle and Del Giudice (2011) suggest that disorganization is 
negatively correlated with cognitive engagement strategies, but unrelated to a host of other active or avoidant coping skills.

\section{Methodological Considerations}

A number of methodological factors were identified during review of the articles that should be considered. First, several studies found that males were more likely to display disorganization than females (Barone et al., 2009; Green et al., 2007; Hygen et al., 2014; Pace et al., 2014) whereas a number of studies did not find such a relationship (Barone et al., in press; Barone \& Lionetti, 2012b; Futh et al., 2008, Wan, Danquah, \& Mahama, in press). However, no studies suggested that disorganization was more prevalent among females. The current metaanalysis found non-significant results for gender, but the $\mathrm{p}$-value obtained $(p=.076)$ approached the customary level of statistical significance, and the direction of the relationship was such that males were more likely to be classified as disorganized. Del Giudice (2008), analyzing the same data used by Colle and Del Giudice (2011), found evidence that a classification approach may obscure gender differences that become apparent when a dimensional approach to scoring disorganization is used. It is advised that researchers examine their own data for a potential impact of gender

Second, younger children were more likely to have disorganization coded than their older counterparts in many studies (Barone et al., 2009; Green et al., 2007; Green et al., 2000; Pasalich et al., 2012), although this finding was not uniform (Barone \& Lionetti, 2012b; Futh et al., 2008; Pritchett, Rochat, Tomlinson, \& Minnis, 2013). In the meta-analysis conducted here, age was not related to disorganization classification. Similarly, a few studies found that lower levels of cognitive ability were related to a greater rating of disorganization (Futh et al., 2008; Hygen et al., 2014) while others did not find such a relationship (Pace et al., 2012; Pasalich et al., 2012). 
The relatively few studies examining cognitive ability and the differences in how that variable was conceptualized (e.g., picture vocabulary, verbal IQ) precluded the use of meta-analysis to determine effect. Researchers may wish to consider assessing cognitive ability and examining whether it, or age of the child, relates to outcomes of interest on the MCAST.

It is worth noting that one glaring methodological challenge was present when interpreting the MCAST literature. Given that attachment relationships are conceptualized as caregiver-specific and the MCAST is designed to assess caregiver-specific representations, it is possible that ratings may differ based on the caregiver identified during administration of the procedure. Although to our knowledge the birth mother was the identified caregiver in most nonadoptive samples, the specific identity of the caregiver involved in the administration of the MCAST was rarely sufficiently identified within the studies reviewed. For example, in studies conducted with adopted and/or institutionalized samples, it was often unclear if the mother doll was associated with the biological or adopted caregiver. In order to draw more precise conclusions about rates of disorganization as well as associations between disorganization and parental factors, in particular, we recommend that the caregiver referenced during the MCAST administration is specifically identified during reporting of the results.

\section{Discussion}

A number of story stem measures are available to assess attachment representations of children. The MCAST is one such technique that has become popular in recent years and one whose coding gives particular attention to attachment disorganization for use in clinical samples. Given the importance of attachment disorganization for clinical and developmental research, we focused specifically on examining the use of the MCAST to assess this construct. 
First, the inter-rater reliability of the MCAST appears satisfactory. Numerous studies document a high level of agreement across raters when coding discrete classifications with both percent agreement and kappa statistics consistently in ranges typically considered acceptable or excellent. Only three studies examined inter-rater consistency for disorganization when considered in a continuous manner and each study suggested excellent agreement among raters.

Second, the validity of the MCAST was assessed by examining five hypotheses constructed a priori. The first hypothesis specified the expected frequency with which disorganization would be identified on the MCAST across sample types. As expected, the frequency of disorganization on the MCAST approximated the frequency of disorganization observed for analogous constructs assessed with widely accepted instruments. For example, roughly $15 \%$ of infants from community samples are classified D in the SSP (van IJzendoorn et al., 1999) and $18 \%$ of adults in community samples are classified U on the AAI (BakermansKranenburg \& van IJzendoorn, 2009). We found that, of the 1,087 children from community samples who completed the MCAST in reviewed studies, $16.2 \%$ were classified D.

The second hypothesis suggested that disorganization on the MCAST would be related to child maltreatment. Indeed, samples of maltreated/adopted children displayed higher frequencies (36\%) of being classified D on the MCAST than samples of children from the community. Beyond this broad finding, little information was available to examine this hypothesis more thoroughly. Only two studies examined this relationship in greater detail and both examined children who were adopted or living in institutions. These two studies found that the amount of time the child was living in substitute care was unrelated to the level of disorganization, potentially suggesting that disorganization as assessed by the MCAST is fairly resistant to 
improvements in caregiving environment. Other explanations are plausible and greater research on this topic is warranted.

The third hypothesis was that disorganization on the MCAST would be related to externalizing and internalizing problems of children. This hypothesis was supported by the finding that $40.4 \%$ of the children drawn from clinical samples were classified D on the MCAST, a significantly greater proportion than those from community samples. Nonetheless, within sample correlations of disorganization with various clinical metrics provided conflicting results. As it pertains to externalizing problems, correlations computed with meta-analysis were generally small in magnitude and were statistically significant for teachers, but not caregivers. However, these findings should be viewed with caution because of the relatively few samples included and the finding that significant variability was present across samples. When examining internalizing problems, a surprising negative correlation was observed for caregiver-reported concerns. One potential hypothesis for this finding is that caregivers more sensitively attached with their child will also be more alert and sensitive to their mental state and, in consequence, show a response bias towards increased reporting of internalized symptoms; with less sensitive caregivers showing the opposite bias. This hypothesis is supported by the teacher-reported concerns being significantly different from the results obtained when looking at caregivers.

The fourth hypothesis stated that disorganization on the MCAST would correlate with developmental constructs, such as poorer social competence and emotion regulation. When examining social competence with meta-analysis, disorganization was not generally found to correlate with poorer social skills as assessed by either caregiver or teacher reports. Few studies examined emotion regulation and results were mixed. The studies generally found that disorganization was related to poorer emotion identification and understanding. In terms of 
emotion regulation strategies, there were various expected and unexpected findings, but no replicated results.

The last hypothesis was that frightening and/or insensitive parental behavior would predict a greater level of disorganization on the MCAST. Surprisingly, relatively little research is available to evaluate this hypothesis. Only one study examined the relationship between the AAI of a biological parent and MCAST of the child, and the expected relationship between U and D classifications, respectively, was present. A second study using the AAI examined the concordance of these classifications with adopted mother/child dyads and few relationships were found. Studies examining caregiver attributes (e.g., expressed emotion, perceived caregiver helplessness) failed to demonstrate any clear relationships. Only two studies, collectively including 131 children, examined the relationship of observed parental behavior with disorganization on the MCAST and no significant relationships were observed.

\section{Future Directions}

In the 17 years since its first publication, the MCAST has found widespread usage as an instrument for clinical assessment, for instance being recommended within the National Institute for Health and Care Excellence (2015) guidelines as well as in other reviews (O'Connor \& Byrne, 2007; Phelps \& Lewis, 2010). The MCAST has also generated a relatively substantial amount of empirical research, as highlighted in this review, which has illuminated a number of aspects of normative and psychopathological development. For instance, the results of the current meta-analysis suggest differing levels of quality in the attachment representations of different groups, such as adopted children and those with clinical psychopathology. Additionally, the percentage of D classifications among general community samples (16.2\%) was similar to the proportion of analogous constructs found in infant and adult samples using other well- 
validated methods. These are encouraging achievements, which reflect the intention of the instrument to be used for both clinical practice and research. The reliability and validity of the MCAST as discussed here provides a relatively sound base that could provide a platform for more extended and detailed developmental research; and there are many possibilities.

Firstly, there remains some basic developmental questions. Theory, as well as data to date, suggests that attachment representations form a key mediating process between experienced environmental risk and developmental outcomes. Studies utilizing the MCAST could illuminate further the biological-environmental interplay at the level of mental state, for instance by being included in genetically informed designs or those studying differential susceptibility based on genetic or biological risk. Perhaps such studies may provide answers to explain the conflicting within-sample results identified within this review.

Secondly, in further efforts to understand how attachment representations operate causally in development, more work needs to investigate the evolution of attachment representations over time in different groups, specifically their stability and the assumed integration of early multiple caregiver-specific representations into a single representation as seen in adulthood. There has not been enough longitudinal work of this kind to date and additional studies incorporating measures of attachment representations, such as the Minnesota Study of Risk and Adaptation (Sroufe, Egeland, Carlson, \& Collins, 2005), would be valuable. They would not only provide important clinically-relevant information on the evolution of attachment through childhood, but provide windows more generally into the dynamics of cognitive and emotional development, the processing of adversity, and mechanisms of vulnerability and resilience. 
Thirdly, the MCAST provides a systematic way of investigating a key issue raised by John Bowlby, which still remains under-investigated; namely, how modifiable are IWMs and which experiences or interventions will be most appropriate and effective to allow such modification? A related question is how the MCAST can be used to investigate treatment mechanisms and outcomes. Can we compare systemic/parent interventions with individual therapy? Could individual therapy designed to directly target IWMs be more effective than generic child therapy? Do pre-treatment IWMs predict response to treatment, and how does any change in IWMs relate to behavioral outcomes as a result of treatment? These are just some of the key questions in determining whether we can design interventions to improve developmental trajectories at an individual level for children. Rigorous investigation of such questions will require large-scale randomized controlled trials designed to test processes and mechanisms, as well as outcomes. Given the promise of the attachment representation construct, and the psychometric properties reviewed here, the MCAST could be considered a promising tool to include within such studies.

\section{References}

Ainsworth, M. D. S., Blehar, M. C., Waters, E., \& Wall, S. N. (1978). Patterns of attachment: A psychological study of the strange situation. Oxford, England: Lawrence Erlbaum.

Bakermans-Kranenburg, M. J., \& van IJzendoorn, M. H. (2009). The first 10,000 adult attachment interviews: Distributions of adult attachment representations in clinical and non-clinical groups. Attachment \& Human Development, 11, 223-263.

*Barone, L., Del Giudice, M., Fossati, A., Manaresi, F., Perinetti, B. A., Colle, L., \& Veglia, F. (2009). Psychometric properties of the Manchester Child Attachment Story Task: An Italian multicentre study. International Journal of Behavioral Development, 33, 185-190.

*Barone, L., Dellagiulia, A., \& Lionetti, F. (in press). When the primary caregiver is missing: Investigating proximal and distal variables involved in institutionalised children's adjustment. Child Abuse Review.

*Barone, L., \& Lionetti, F. (2012a). Attachment and emotional understanding: A study on late- 
adopted pre-schoolers and their parents. Child: Care, Health, and Development, 38, 690696.

*Barone, L., \& Lionetti, F. (2012b). Attachment and social competence: A study using MCAST in low-risk Italian preschoolers. Attachment \& Human Development, 14, 391-403.

Berg-Nielsen, T. S., Solheim, E., Belsky, J., \& Wichstrom, L. (2012). Preschoolers' psychosocial problems: In the eyes of the beholder? Adding teacher characteristics as determinants of discrepant parent-teacher reports. Child Psychiatry and Human Development, 43, 393413.

Bernard, K., \& Dozier, M. (2010). Examining infants' cortisol responses to laboratory tasks among children varying in attachment disorganization: Stress reactivity or return to baseline? Developmental Psychology, 46, 1771-1778.

Borenstein, M., Hedges, L. V., Higgins, J. P. T., \& Rothstein, H. R. (2009). Introduction to meta-analysis. Chichester, West Sussex, UK: Wiley.

Bowlby, J. (1973). Attachment and loss: Vol. 2. Separation: Anxiety and anger. New York: Basic Books.

Bowlby, J. (1980). Attachment and loss: Vol. 3. Loss: Sadness and depression. New York: Basic Books.

Bowlby, J. (1982). Attachment and loss: Vol. 1. Attachment. (2 $2^{\text {nd }}$ ed.). New York: Basic Books. (Original work published 1969).

Bowlby, J. (1988). A secure base: Parent-child attachment and healthy human development. New York: Basic Books.

Bretherton, I. (2005). In pursuit of the internal working model construct and its relevance to attachment relationships. In K. E. Grossmann, K. Grossmann, \& E. Waters (Eds.), Attachment from infancy to adulthood: The major longitudinal studies. (pp. 13-47). New York: Guilford Press.

Bretherton, I., \& Munholland, K. A. (2008). Internal working models in attachment relationships: Elaborating a central construct in attachment theory. In J. Cassidy \& P. R. Shaver (Eds.), Handbook of Attachment: Theory, Research, and Clinical Applications. ( $2^{\text {nd }}$ ed.). (pp. 102-127). New York: Guilford Press.

Bretherton, I., Ridgeway, D., \& Cassidy, J. (1990). Assessing internal working models of the attachment relationship: An attachment story completion task for 3-year-olds. In M. T. Greenberg, D. Cicchetti, \& E. M. Cummings (Eds.), Attachment in the preschool years: Theory, research, and intervention. (pp. 273-308). Chicago: University of Chicago Press.

Cicchetti, D. V. (1994). Guidelines, criteria, and rules of thumb for evaluating normed and 
standardized assessment instruments in psychology. Psychological Assessment, 6, 284290.

Cohen, J. (1960). A coefficient of agreement for nominal scales. Educational and Psychological Measurement, 20, 37.

*Colle, L., \& Del Giudice, M. (2011). Patterns of attachment and emotional competence in middle childhood. Social Development, 20, 51-72.

Comprehensive Meta-Analysis (Version 3). [Compute software]. Englewood, NJ: Biostat.

Cooke, J. E., Stuart-Parrigon, K. L., Movahed-Abtahi, M., Koehn, A. J., \& Kerns, K. A. (in press). Children's emotion understanding and mother-child attachment: A meta-analysis. Emotion.

Cyr, C., Euser, E. M., Bakermans-Kranenburg, M. J., \& van IJzendoorn, M. H. (2010). Attachment security and disorganization in maltreating and high-risk families: A series of meta-analyses. Development and Psychopathology, 22, 87-108.

De Wolff, M. S., \& van IJzendoorn, M. H. (1997). Sensitivity and attachment: A meta-analysis on parental antecedents of infant attachment. Child Development, 68, 571-591.

Del Giudice, M. (2008). Sex-based ratio of avoidant/ambivalent attachment in middle childhood. British Journal of Developmental Psychology, 26, 369-379.

Emde, R. N., Wolf, D. P., \& Oppenheim, D. (Eds.; 2003). Revealing the inner worlds of young children: The MacArthur Story Stem Battery and parent-child narratives. New York: Oxford University Press.

Fearon, R. P., Bakermans-Kranenburg, M. J., van IJzendoorn, M. H., Lapsley, A. M., \& Roisman, G. I. (2010). The significance of insecure attachment and disorganization in the development of children's externalizing behavior: A meta-analytic study. Child Development, 81, 435-456.

*Futh, A., O’Connor, T. G., Matias, C., Green, J., \& Scott, S. (2008). Attachment narratives and behavioral and emotional symptoms in an ethnically diverse, at-risk sample. Journal of the American Academy of Child and Adolescent Psychiatry, 47, 709-718.

George, C., Kaplan, N., \& Main, M. (1985). Adult Attachment Interview. Unpublished manuscript. University of California, Berkeley.

George, C., \& Solomon, J. (1990-2016). Attachment Doll Play Assessment and Classification System. Oakland, CA: Mills College.

*Goldwyn, R., Stanley, C., Smith, V., \& Green, J. (2000). The Manchester Child Attachment 
Story Task: Relationship with parental AAI, SAT, and child behaviour. Attachment \& Human Development, 2, 71-84.

Green, J., Stanley, C., Goldwyn, R., \& Smith, V. (2016). Coding manual for the Manchester Child Attachment Story Task (v. 29). Manchester, UK: University of Manchester.

*Green, J., Stanley, C., \& Peters, S. (2007). Disorganized attachment representation and atypical parenting in young school age children with externalizing disorder. Attachment and Human Development, 9, 207-222.

*Green, J., Stanley, C., Smith, V., \& Goldwyn, R. (2000). A new method of evaluating attachment representations in young school-age children: The Manchester Child Attachment Story Task. Attachment \& Human Development, 2, 48-70.

Groh, A. M., Fearon, R. P., Bakermans-Kranenburg, M. J., van IJzendoorn, M. H., Steele, R. D., \& Roisman, G., I. (2014). The significance of attachment security for children's social competence with peers: A meta-analytic study. Attachment \& Human Development, 16, 103-136.

Groh, A. M., Roisman, G. I., van IJzendoorn, M. H., Bakermans-Kranenburg, M. J., \& Fearon, R. P. (2012). The significance of insecure and disorganized attachment for children's internalizing symptoms: A meta-analytic study. Child Development, 83, 591-610.

Hesse, E. (2016). The Adult Attachment Interview: Protocol, method of analysis, and empirical studies: 1985-2015. In J. Cassidy \& P. R. Shaver (Eds.), Handbook of Attachment: Theory, Research, and Clinical Applications. ( $3^{\text {rd }}$ ed.). (pp. 553 - 597). New York; Guilford Press.

Higgins, J., Thompson, S. G., Deeks, J. J., \& Altman, D. G. (2003). Measuring inconsistency in meta-analyses. BMJ, 327, 557-560.

*Hygen, B. W., Guzey, I. C., Belsky, J., Berg-Nielsen, T. S., \& Wichstrøm, L. (2014). Catechol$O$-methyltransferase Val158Met genotype moderates the effect of disorganized attachment on social development in young children. Development and Psychopathology, 26, 947-961.

*Kočovská, E., Puckering, C., Follan, M., Smillie, M., Gorski, C., Barnes, J., ... Minnis, H. (2012). Neurodevelopmental problems in maltreated children referred with indiscriminate friendliness. Research in Developmental Disabilities, 33, 1560-1565.

*Leuzinger-Bohleber, M., Laezer, K. L., Pfenning-Meerkoetter, N., Fischmann, T., Wolff, A., \& Green, J. (2011). Psychoanalytic treatment of ADHD children in the frame of two extraclinical studies: The Frankfurt Prevention Study and the EVA Study. Journal of Infant, Child, and Adolescent Psychotherapy, 10, 32-50.

Madigan, S., Atkinson, L., Laurin, K., \& Benoit, D. (2013). Attachment and internalizing 
behavior in early childhood: A meta-analysis. Developmental Psychology, 49, 672-689.

Madigan, S., Brumariu, L. E., Villani, V., Atkinson, L., \& Lyons-Ruth, K. (2016).

Representational and questionnaire measures of attachment: A meta-analysis of relations to child internalizing and externalizing problems. Psychological Bulletin, 142, 367-399.

Madigan, S., Moran, G., \& Pederson, D. R. (2006). Unresolved states of mind, disorganized attachment relationships, and disrupted interactions of adolescent mothers and their infants. Developmental Psychology, 42, 293-304.

Main, M., \& Cassidy, J. (1988). Categories of response to reunion with the parent at age 6: Predictable from infant attachment classifications and stable over a 1-month period. Developmental Psychology, 24, 415-426.

Main, M., Kaplan, N., \& Cassidy, J. (1985). Security in infancy, childhood, and adulthood: A move to the level of the representation. Monographs of the Society for Research in Child Development, 50, 66-104.

Main, M., \& Solomon, J. (1986). Discovery of a new, insecure-disorganized/disoriented attachment pattern. In M. Yogman \& T. B. Brazelton (Eds.), Affective development in infancy (pp. 95-124). Norwood, NJ: Ablex.

Main, M., \& Solomon, J. (1990). Procedures for identifying infants as disorganized/disoriented during the Ainsworth Strange Situation. In M. T. Greenberg, D. Cicchetti, \& E. M. Cummings (Eds.), Attachment in the preschool years: Theory, research, and intervention. (pp. 121-160). Chicago: University of Chicago Press.

*Matias, C., O’Connor, T. G., Futh, A., \& Scott, S. (2014). Observational attachment theorybased parenting measures predict children's attachment narratives independently from social learning theory-based measures. Attachment \& Human Development, 16, 77-92.

McHugh, M. L. (2012). Inter-rater reliability: The kappa statistic. Biochemica Medica, 22, 276282.

*Messina, S., \& Zavattini, G. C. (2014). How do children make sense of their experiences? Children's memories of wellbeing and distress from an attachment perspective. International Journal of Behavioral Development, 38, 209-218.

*Minnis, H., Green, J., O’Connor, T. G., Liew, A., Glaser, D., Taylor, E., ... Sadiq, F. A. (2009). An exploratory study of the association between reactive attachment disorder and attachment narratives in early school-age children. Journal of Child Psychology and Psychiatry, 50, 931-942.

*Minnis, H., Read, W., Connolly, B., Burston, A., Schumm, T., Putter-Lareman, S., \& Green, J. 
(2010). The Computerised Manchester Child Attachment Story Task: A novel medium for assessing attachment patterns. International Journal of Methods in Psychiatric Research, 19, 233-242.

National Institute for Health and Care Excellence. (2015). Children's attachment: Attachment in children and young people who are adopted from care, in care, or at high risk of going into care. London: Author.

O’Connor, T. G., \& Byrne, J. G. (2007). Attachment measures for research and practice. Child and Adolescent Mental Health, 12, 187-192.

*Pace, C. S., Cavanna, D., Velotti, P., \& Zavattini, G. C. (2014). Attachment representations in late-adopted children: The use of narrative in the assessment of disorganization, mentalising and coherence of mind. Adoption and Fostering, 38, 255-270.

*Pace, C. S., \& Zavattini, G. C. (2011). Adoption and attachment theory: The attachment models of adoptive mothers and the revision of attachment patterns of their late-adopted children. Child: Care, Health, \& Development, 37, 82-88.

*Pace, C. S., Zavattini, G. C., \& D’Alessio, M. (2012). Continuity and discontinuity of attachment patterns: A short-term longitudinal pilot study using a sample of late-adopted children and their adoptive mothers. Attachment and Human Development, 14, 45-61.

*Pasalich, D. S., Dadds, M. R., Hawes, D. J., \& Brennan, J. (2012). Attachment and callousunemotional traits in children with early-onset conduct problems. Journal of Child Psychology and Psychiatry, 53, 838-845.

Phelps, N., \& Lewis, A. J. (2010). The assessment and treatment of a child with an attachment disorder. In A. J. Lewis, E. Gould, C. Habib, \& R. King (Eds.), Integrative assessment in clinical psychology. Sydney: Australian Academic Press.

*Pritchett, R., Minnis, H., Puckering, C., Rajendran, G., \& Wilson, P. (2013). Can behaviour during immunisation be used to identify attachment patterns? A feasibility study. International Journal of Nursing Studies, 50, 386-391.

*Pritchett, R., Rochat, T. J., Tomlinson, M., \& Minnis, H. (2013). Risk factors for vulnerable youth in urban townships in South Africa: The potential contribution of reactive attachment disorder. Vulnerable Children and Youth Studies, 8, 310-320.

Roisman, G. I., Tsai, J. L., \& Chiang, K. S. (2004). The emotional integration of childhood experience: Physiological, facial expression, and self-reported emotional response during the Adult Attachment Interview. Developmental Psychology, 40, 776-789.

Solomon, J., \& George, C. (2016). The measurement of attachment security and related 
constructs in infancy and early childhood. In J. Cassidy \& P. R. Shaver (Eds.), Handbook of Attachment: Theory, Research, and Clinical Applications. ( $3^{\text {rd }}$ ed.). (pp. 366 - 396). New York; Guilford Press.

Southam-Gerow, M. A. (2013). Emotion regulation in children and adolescents: A practitioner's guide. New York: Guilford Press.

Sroufe, L. A., Egeland, B., Carlson, E. A., \& Collins, W. A. (2005). The development of the person: The Minnesota Study of Risk and Adaptation from birth to adulthood. New York: Guilford Press.

van IJzendoorn, M. H., Schuengel, C., \& Bakermans-Kranenburg, M. J. (1999). Disorganized attachment in early childhood: Meta-analysis of precursors, concomitants, and sequelae. Development and Psychopathology, 11, 225-249.

*Wan, M. W., Danquah, A. N., \& Mahama, S. (in press). Child-caregiver attachment representations in a non-Western context: The feasibility and cultural equivalence of story stems in urban Ghana. Social Development.

*Wan, M. W., Warburton, A. L., Appleby, L., \& Abel, K. M. (2007). Mother and baby unit admissions: Feasibility study examining child outcomes 4-6 years on. Australian and New Zealand Journal of Psychiatry, 41, 150-156.

Waters, H. S., \& Waters, E. (2006). The attachment working models concept: Among other things, we build script-like representations of secure base experiences. Attachment \& Human Development, 8, 185-197.

Waters, T. E. A., Brockmeyer, S. L., \& Crowell, J. A. (2013). AAI coherence predicts caregiving and care seeking behavior: Secure base script knowledge explains why. Attachment \& Human Development, 15, 316-331.

*Zaccagnino, M., Cussino, M., Callerame, C., Perinetti, B. A., Veglia, F., \& Green, J. (2013). Attachment and social understanding in young school-age children: An investigation using the Manchester Child Attachment Story Task. Minerva Psichiatrica, 54, 59-69.

*Indicates a study included in the review. 
Figure 1: Identification and selection of studies for inclusion.

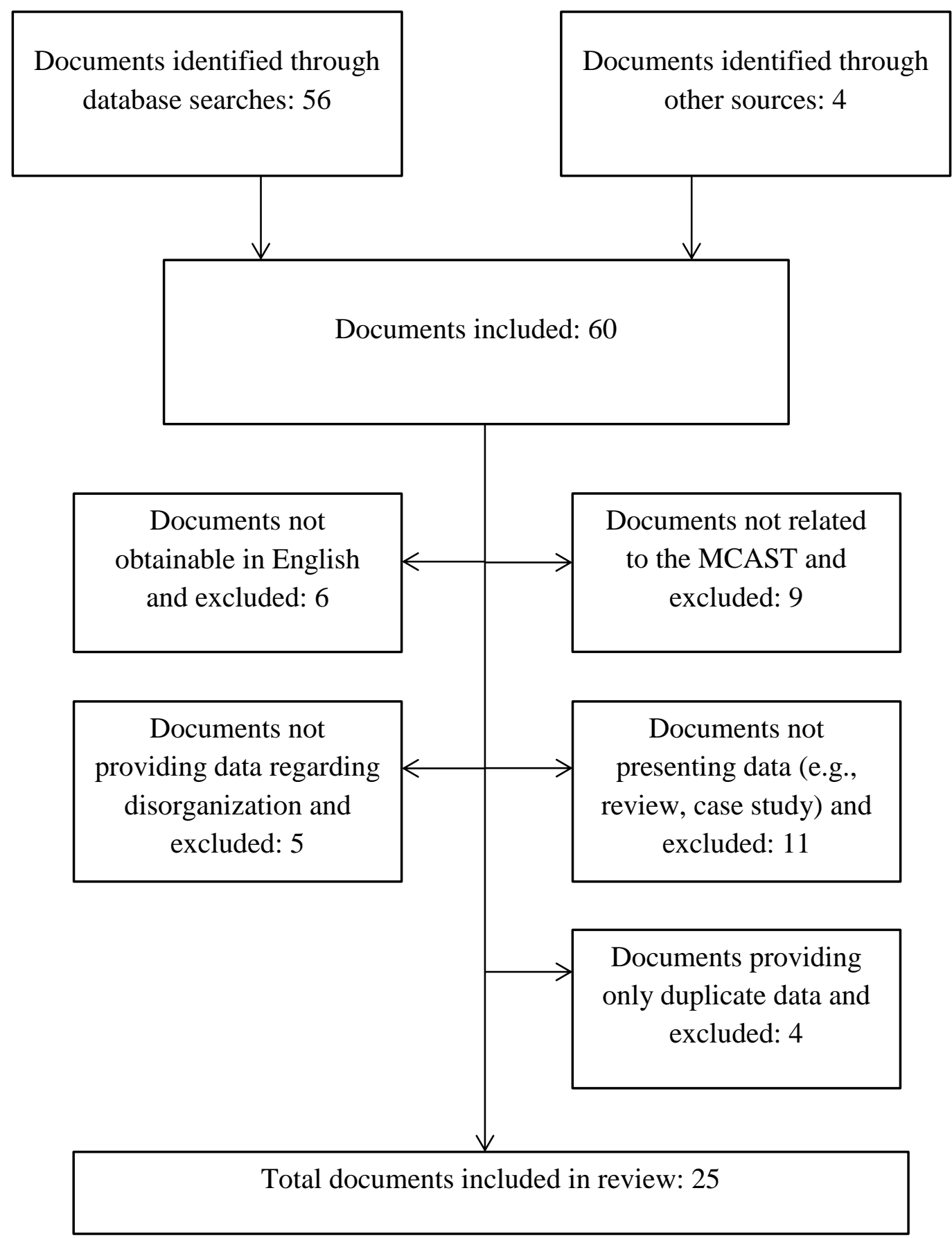


Table 1: Studies examining disorganization using the Manchester Child Attachment Story Task

\begin{tabular}{|c|c|c|c|c|c|c|}
\hline Source & $\begin{array}{l}\text { Child } \\
\text { Sample(s) }\end{array}$ & $\begin{array}{l}\text { Inter-rater } \\
\text { Agreement }\end{array}$ & $\begin{array}{l}\text { Gender } \\
\text { (\% male) }\end{array}$ & $\begin{array}{l}\text { Mean } \\
\text { Age (months) }\end{array}$ & $\begin{array}{l}\text { Criterion } \\
\text { Measure(s) }\end{array}$ & Results \\
\hline Barone et al. (2009) & 230 non-clinical & Four-way: $78 \%$ & $50 \%$ & 80.8 & None & 1. $11 \%$ classified $\mathrm{D}$ on the MCAST \\
\hline $\begin{array}{l}\text { Barone, Dellagiulia, } \\
\text { \& Lionetti } \\
\text { (in press) }\end{array}$ & $\begin{array}{l}39 \text { maltreated \& } \\
\text { institutionalized }\end{array}$ & $\begin{array}{l}\text { Four-way: } 83 \% \\
\quad(k=.87)\end{array}$ & $33 \%$ & 71.5 & CHQ & $\begin{array}{l}\text { 1. } 38.5 \% \text { classified D on the MCAST } \\
\text { 2. Children significantly more likely to be } \\
\text { classified D than children in a non- } \\
\text { clinical sample (Barone et al., 2009). } \\
\text { 3. D classification not related to length of } \\
\text { time in the institution or a preferred } \\
\text { caregiver's reported helplessness as a } \\
\text { caregiver. }\end{array}$ \\
\hline $\begin{array}{l}\text { Barone \& Lionetti } \\
(2012 \mathrm{a})\end{array}$ & 20 adopted & $\begin{array}{c}\text { Four-way: } \\
k=.70\end{array}$ & $80 \%$ & 58.8 & TEC & $\begin{array}{l}\text { 1. } 35 \% \text { classified D on the MCAST } \\
\text { 2. Adopted children more likely to be } \\
\text { classified D when compared to normative } \\
\text { sample from Barone et al. (2009). } \\
\text { 3. D classification correlated with poorer } \\
\text { emotional understanding. }\end{array}$ \\
\hline $\begin{array}{l}\text { Barone \& Lionetti } \\
(2012 b)\end{array}$ & 64 non-clinical & Four-way: $80 \%$ & $50 \%$ & 61.9 & SCBE & $\begin{array}{l}\text { 1. } 12 \% \text { classified D on the MCAST } \\
\text { 2. MCAST D classification related to less } \\
\text { social competence, more internalizing and } \\
\text { externalizing problems, and poorer } \\
\text { general adaptation as reported by } \\
\text { teachers. }\end{array}$ \\
\hline $\begin{array}{l}\text { Colle \& Del Giudice } \\
\text { (2011) }\end{array}$ & $\begin{array}{l}122 \text { non-clinical } \\
\text { (subset of sample } \\
\text { included in } \\
\text { Barone, et al. } \\
{[2009] \text { ) }}\end{array}$ & $\begin{array}{c}\text { Four-way: } \\
k=.81\end{array}$ & $42 \%$ & 86.4 & $\begin{array}{l}\text { Emotion } \\
\text { recognition \& } \\
\text { regulation tasks }\end{array}$ & $\begin{array}{l}\text { 1. D classification correlated with poorer } \\
\text { non-verbal emotion discrimination. } \\
\text { 2. No relationship between disorganization } \\
\text { and verbal labeling of emotions. } \\
\text { 3. D classification negatively correlated with } \\
\text { cognitive engagement emotion regulation } \\
\text { strategies; not associated with behavioral } \\
\text { engagement, behavioral diversion, or } \\
\text { cognitive diversion strategies; or for } \\
\text { helplessness responses. }\end{array}$ \\
\hline
\end{tabular}


Futh, O’Connor,

Matias, Green,

Scott (2008)
113 non-clinical, Four-way: 80\% 48\%

\& at-risk

$(k=.66)$
66.0

SDQ

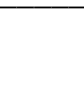

(n)

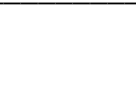

\begin{tabular}{|c|c|c|c|c|c|}
\hline $\begin{array}{l}\text { Goldwyn, Stanley, } \\
\text { Smith, \& Green } \\
(2000)\end{array}$ & 53 non-clinical & $\begin{array}{l}\text { Two-way: } 82 \% \\
\quad(k=.41) \\
\text { Total D score: } \\
\text { ICC }=.76\end{array}$ & $\begin{array}{l}\text { See Green } \\
\text { et al. }(2000)\end{array}$ & $\begin{array}{l}\text { See Green } \\
\text { et al. }(2000)\end{array}$ & $\begin{array}{l}\text { AAI } \\
\text { EAS } \\
\text { CBCL }\end{array}$ \\
\hline
\end{tabular}


3. Continuity of total D score observed at follow-up assessment $(\mathrm{ICC}=.70)$.

\begin{tabular}{cccc}
\hline Hygen et al. (2014) & 531 non-clinical & Total D Score: & $51 \%$ \\
ICC $=.76^{*}$ & & 54.8 & CBCL \\
SSRS
\end{tabular}

1. $23.5 \%$ classified as "highly disorganized" on the MCAST.*

2. Disorganization positively correlated with caregiver-reported aggression; negatively correlated with caregiver-reported social skills.

3. Disorganization negatively correlated with teacher-reported social competence; not related to teacherreported concurrent aggression.

\begin{tabular}{|c|c|c|c|c|c|c|}
\hline $\begin{array}{l}\text { Kočovská et al. } \\
\text { (2012) }\end{array}$ & $\begin{array}{l}34 \text { adopted; } \\
32 \text { nonclinical }\end{array}$ & N/A & $\begin{array}{l}53 \% \\
53 \%\end{array}$ & $\begin{array}{l}112.8 \\
104.4\end{array}$ & None & $\begin{array}{l}\text { 1. } 32.4 \% \text { of adopted children classified D on } \\
\text { the MCAST; } 3.1 \% \text { of biological classified } \\
\text { D. }\end{array}$ \\
\hline $\begin{array}{l}\text { Leuzinger-Bohleber, } \\
\text { et al. (2011) }\end{array}$ & $\begin{array}{l}234 \text { non-clinical, } \\
\text { at-risk }\end{array}$ & $\begin{array}{c}\text { Four-way: } \\
\quad k=.62\end{array}$ & $48 \%$ & 50.4 & None & 1. $23 \%$ classified D on the MCAST. \\
\hline $\begin{array}{l}\text { Matias, O'Connor, } \\
\text { Futh, \& Scott (2014) }\end{array}$ & $\begin{array}{l}\text { See Futh et al. } \\
(2008)\end{array}$ & $\begin{array}{l}\text { See Futh et al. } \\
(2008)\end{array}$ & $\begin{array}{l}\text { See Futh et al. } \\
(2008)\end{array}$ & $\begin{array}{l}\text { See Futh et al. } \\
\text { (2008) }\end{array}$ & CARP & $\begin{array}{l}\text { 1. Observational assessment of } \\
\text { attachment-related parenting not } \\
\text { associated with total D score.* }\end{array}$ \\
\hline $\begin{array}{l}\text { Messina \& Zavattini } \\
(2014)\end{array}$ & 30 nonclinical & $\begin{array}{l}\text { Four-way: } 95 \% \\
\quad(k=.92)\end{array}$ & $66 \%$ & 78.8 & None & 1. Did not examine disorganization. \\
\hline Minnis, et al. (2009) & $\begin{array}{l}37 \text { non-clinical; } \\
33 \text { clinical }\end{array}$ & $\begin{array}{l}\text { Four-way: } \\
\quad k=.93\end{array}$ & $67 \%$ & 77.3 & None & $\begin{array}{l}\text { 1. } 27 \% \text { of clinical group classified D on the } \\
\text { MCAST; } 0 \% \text { of the non-clinical group } \\
\text { (odds ratio }=2.4, p=.001 \text { ). } \\
\text { 2. Clinical children scored significantly } \\
\text { higher for total D score than non-clinical } \\
\text { children. }\end{array}$ \\
\hline Minnis et al. (2010) & $\begin{array}{l}55 \text { clinical } \\
\text { and nonclinical }\end{array}$ & $\begin{array}{l}\text { Four-way: } 96 \% \\
\quad(k=.93)\end{array}$ & $66 \%$ & 81.6 & None & 1. $7.2 \%$ classified D on the MCAST. \\
\hline
\end{tabular}


Pace, Cavanna,

60 adopted

Velotti, \& Zavattini

(2014)

\begin{tabular}{llllll}
\hline Pace \& Zavattini & 11 non-clinical; & See Pace et al. & $45 \%$ & 71.7 & None \\
(2011) & 27 adopted & $(2014)$ & & \\
& (subset of Pace & & & \\
& et al., [2014]) & & &
\end{tabular}

1. $37 \%$ classified D on the MCAST.

2. Total D score negatively correlated with age at adoption.

3. Total D score not associated with time in placement.

. $37 \%$ of adopted children classified D;

$18 \%$ of nonclinical/biological children

classified D.

2. Difference in rate of $\mathrm{D}$ classification between adopted and biological children not statistically significant.

3. Adopted children scored significantly higher on the Total D score than nonclinical, biological children.
Pace, Zavattini, \&

D’Alessio (2012)
28 adopted

(subset of Pace

et al. [2014])
See Pace et al. $\quad 46 \%$

(2014)
70.0

SRP

AAI
1. MCAST D classification not related to D classification in the SRP (Note: no children classified as disorganized in the SRP).

2. MCAST total D score positively correlated with 'idealization of mother' scale on the AAI ; no other relationships with the AAI scales or classifications.

\begin{tabular}{|c|c|c|c|c|c|}
\hline $\begin{array}{l}\text { Pasalich, Dadds, } \\
\text { Hawes, \& Brennan } \\
\text { (2012) }\end{array}$ & $\begin{array}{l}55 \text { clinical, with } \\
\text { externalizing } \\
\text { problems }\end{array}$ & $\begin{array}{l}\text { Two-way: } \\
\quad k=.81 \\
\text { Total D Score: } \\
\text { ICC }=.88\end{array}$ & $100 \%$ & 75.7 & UNSW system \\
\hline
\end{tabular}

1. 36\% classified D on the MCAST.

2. D classification positively correlated with callous/unemotional traits.

3. Total D score positively correlated with callous/unemotional traits.

\begin{tabular}{|c|c|c|c|c|c|c|}
\hline Pritchett et al. (2013) & 18 non-clinical & N/A & $67 \%$ & 49.4 & MPOS & $\begin{array}{l}\text { 1. } 22.2 \% \text { classified D on the MCAST. } \\
\text { 2. D classification not correlated with } \\
\text { positive parenting behaviors; also not } \\
\text { correlated with pain reducing or } \\
\text { promoting behaviors during child } \\
\text { immunization. }\end{array}$ \\
\hline Pritchett et al. (2013) & $\begin{array}{l}40 \text { non-clinical, } \\
\text { at-risk }\end{array}$ & N/A & $50 \%$ & 118.4 & None & $\begin{array}{l}\text { 1. } 23 \% \text { classified D on the MCAST } \\
2.19 \% \text { of children classified D in the S }\end{array}$ \\
\hline
\end{tabular}


18 months of age were classified D on the MCAST at 10 years of age; $21.4 \%$

classified secure in the SSP classified D on the MCAST.

\begin{tabular}{|c|c|c|c|c|c|c|}
\hline $\begin{array}{l}\text { Wan, Danquah, \& } \\
\text { Mahama (in press) }\end{array}$ & 67 non-clinical & $\begin{array}{l}\text { Four-way: } 80 \% \\
\quad(k=.52)\end{array}$ & $48 \%$ & 87.2 & SDQ & $\begin{array}{l}\text { 1. } 10 \% \text { classified D on the MCAST } \\
\text { 2. Most SDQ scales yielded poor internal } \\
\text { consistency and the disorganized group } \\
\text { was too small, thus analyses were not } \\
\text { performed. }\end{array}$ \\
\hline
\end{tabular}

Wan, Warburton,

15 non-clinical, N/A

$50 \%$

64.6

None

$1.0 \%$ classified D on the MCAST

Appleby, \& Abel at-risk

(2007)

Zaccagnino et al.

$$
\begin{array}{cc}
44 \text { non-clinical } & \text { Two-way: } 80 \% \quad 51 \% \\
& (k=.53) \\
& \text { Four-way: } 80 \% \\
& (k=.52)
\end{array}
$$

75.6

Social cognition
and problem-
solving tasks

1. 27.3\% classified D on the MCAST

2. D classification correlated with higher scores for aggressive problem-solving.

3. Total D scores positively correlated with hostile attributions and aggressive reactions to hostile attributions.

*Modified scoring procedures were utilized for this study; consult original article for details.

Note: AAI = Adult Attachment Interview (Main, Goldwyn, \& Hesse, 2008), CARP = Coding of Attachment-Related Parenting (Stevenson-Hinde \& Shouldice, 1995), $\mathrm{CBCL}=$ Child Behavior Checklist (Achenbach \& Edelbrock, 1981), CFI = Camberwell Family Interview (Vaughn \& Leff, 1976), CHQ = Caregiver Helplessness Questionnaire (George \& Solomon, 2008), EAS = EAS Child Temperament Scale (Buss \& Plomin, 1984), ECBI = Eyberg Child Behavior Inventory (Eyberg \& Ross, 1978), MPOS = Mellow Parenting Observational System (Puckering et al., 1994), RAD = Reactive Attachment Disorder, SAT = Separation Anxiety Test (Slough \& Greenberg, 1990), SCBE = Social Competence and Behavior Evaluation (LaFreniere \& Dumas, 1995), SDQ = Strengths and Difficulties Questionnaire (Goodman, 1999), SRP = Separation and Reunion Procedure (Main \& Cassidy, 1988), SSP = Strange Situation Procedure (Ainsworth et al., 1978), SSRS = Social Skills Rating System (Gresham \& Elliot, 1990), TEC = Test of Emotion Comprehension (Pons \& Harris, 2000), UNSW = University of New South Wales system (Dadds et al., 2005) 